\title{
La voz de las mujeres en las guerras de la Independencia de Colombia: del anonimato a las reivindicaciones*
}

\author{
Roger Pita Pico \\ Academia Colombiana de Historia \\ rogpitc@hotmail.com \\ http://orcid.org/0000-0001-9937-0228
}

\section{RESUMEN}

En el marco de la conmemoración de juzgamiento a adversarios políticos. del Bicentenario de la Independencia de Pero la gran mayoría corresponde a los Colombia, este trabajo tiene como propósito examinar una recopilación de veintiséis cartas escritas por mujeres en medio de la guerra de emancipación. A través de estas cartas es posible asomarnos al complejo mundo que ellas debieron afrontar en estos tiempos de convulsión política y militar. Algunas cartas son declaraciones de defensa, testimonios y denuncias presentadas en el marco de los procesos trámites y esfuerzos que ellas debieron emprender ante las instituciones legalmente establecidas con miras a aliviar la crítica situación económica de sus familias y a lograr mejores condiciones sociales y de subsistencia para sus esposos, hijos y demás seres queridos comprometidos en la lucha militar.

Palabras clave: cartas, mujeres, guerra, Independencia, Colombia, siglo XIX.

Cómo citar: Pita, R. (2020). La voz de las mujeres en las guerras de Independencia de Colombia: del anonimato a las reivindicaciones. Ciencias Sociales y Educación, 9(18), 85-112, https://doi.org/10.22395/csye.v9n18a4 Recibido: 23 de mayo de 2020.

Aprobado: 17 de julio de 2020. 


\section{Women's Voice in the Colombian Wars for Independence: from Anonymity to Caims}

\section{ABSTRACT}

In the context of the commemoration of the Bicentenary of the Colombian Independence, this work has as its main purpose examining a compilation of twenty six letters written by women in the midst of the war for independence. Through this letters it is possible to have a glimpse of the complex world that they decided to confront in times of political and military convulsion. Some of those letters are defense declarations, testimonies and complaints presented in the context of the judgment processes of political adversaries. But most of them correspond to the procedural formalities and efforts they had to endure before the legally constituted institutions with aims towards alleviate the critical economic situation of their families and thus achieving better life conditions and better subsistence opportunities for their husbands, sons and other loved ones involved in the military struggle.

Keywords: letters, women, war, Independence, Colombia, XIXth century.

\section{A voz das mulheres nas guerras pela Independência da Colômbia: do anonimato às reivindicações}

\section{RESUMO}

No marco da comemoração do Bicentenário da Independência da Colômbia, este trabalho tem como objetivo examinar uma compilação de 26 cartas escritas por mulheres em meio à guerra de emancipação. Por meio dessas cartas, é possível observar o mundo complexo que elas tiveram que enfrentar em tempos de convulsão política e militar. Algumas cartas são declarações de defesa, testemunhos e denúncias apresentadas durante o julgamento de opositores políticos. Mas a grande maioria corresponde aos trâmites e esforços que elas tiveram que empreender perante as instituições legalmente estabelecidas com o objetivo de aliviar a crítica situação econômica de suas famílias e alcançar melhores condições sociais e de subsistência para seus maridos, filhos e outros entes queridos envolvidos na luta militar.

Palavras-chave: cartas; Colômbia; guerra; independência; mulheres; século XIX. 


\section{Introducción}

Desde los tiempos del dominio hispánico en la Nueva Granada, ${ }^{1}$ las mujeres estuvieron inmersas en una sociedad jerarquizada y segregacionista, sometidas a la autoridad patriarcal y confinadas a los asuntos domésticos y devocionales. Pese a que no tenían acceso a cargos de poder y eran limitadas sus posibilidades de ingreso a los planteles educativos, hay que resaltar cómo ellas expresaron su voz en situaciones de crisis y en algunas ocasiones lograron una participación activa (De la Pedraja, 1984, p. 225). El advenimiento del periodo revolucionario que comprometió a principios del siglo XIX el territorio hispanoamericano trajo para ellas nuevos retos que las impulsó a ampliar sus espacios de acción.

Dentro de la nueva historia militar y con un ánimo revisionista, el enfoque de género ha conllevado a analizar con objetividad los diferentes roles asumidos por las mujeres en la guerra: desde sus posturas pasivas en sus ámbitos domésticos hasta su situación como víctimas o como partícipes directas en el campo de batalla (Borreguero, 2016, p. 157). Para ello, se hace pertinente extender la mirada más allá de las heroínas que han sido el centro de interés de la historiografía tradicional $^{2}$. Se pretende, entonces, visibilizar con esta apuesta investigativa a mujeres anónimas que de alguna manera ejercieron alguna injerencia en la dinámica de la guerra y se constituyeron como sujetos de la historia (García, 2013).

Al momento de hacer un sucinto balance historiográfico sobre la mujer en la Independencia (Arias, 2015, pp. 146-151), hay que comenzar por mencionar los primeros relatos, como los del funcionario y cronista José Manuel Restrepo, en donde es marcada la invisibilidad de la mujer y la mención de algunas en tono heroico. En las décadas iniciales del siglo XX surgieron algunos escritos sobre la participación femenina, entre ellos los de José María Monsalve (2010), y en la década del setenta fueron publicadas investigaciones más consolidadas como las de Evelyn Cherpak (1995) y Amanda Gómez (1978). Hacia la década del noventa y comienzos del siglo XXI vale resaltar las obras de Aída Martínez (1997) y otra de Alonso Valencia (2001) sobre las mujeres caucanas en la guerra, y el libro de Martha Lux Martelo (2014) sobre las diversas facetas de la vida de las mujeres del común y sus prácticas discursivas. De más reciente data es el libro de la historiadora Judith González (2018) que aborda las representaciones y discursos creados en torno a las mujeres.

En el marco de la conmemoración del Bicentenario de la Independencia de Colombia, este artículo tiene por objeto examinar una recopilación de veintiséis cartas escritas por mujeres en medio de la guerra con el fin de asomarnos

La Nueva Granada comprendía en términos generales el territorio de lo que hoy corresponde a la República de Colombia.

2 Entre los trabajos clásicos de esta visión heroica, está el de (Monsalve, 2010). 
al complejo mundo que ellas debieron afrontar en estos tiempos de convulsión política y militar. Se ha tomado preferentemente como criterio de análisis las mujeres de los sectores populares y medios de la sociedad ${ }^{3}$ porque la mayor cantidad de información disponible hace alusión a las acaudaladas y esposas de gobernantes y altos mandos militares ${ }^{4}$. En los casos aparecen involucradas tanto mujeres adictas al bando republicano como aquellas seguidoras de las banderas del rey.

Algunas cartas son declaraciones de defensa, testimonios y denuncias presentadas en el marco de los procesos de juzgamiento a adversarios políticos. Pero la gran mayoría corresponde a los trámites y esfuerzos que ellas debieron emprender con miras a aliviar la crítica situación económica de sus familias y a mejorar las condiciones sociales y de subsistencia para sus esposos, hermanos, hijos y otros parientes comprometidos en la lucha militar. La tabla 1 sintetiza el tipo de petición de acuerdo con la expectativa o necesidad de la mujer involucrada:

Tabla 1. Tipo de peticiones y reclamaciones de mujeres en la Independencia según la muestra de cartas seleccionadas

\begin{tabular}{llc}
\hline Tipo de reclamaciones & \multicolumn{1}{c}{ Solicitud específica } & Total \\
\hline Políticas & $\begin{array}{l}\text { Declaraciones de apoyo político, solicitud de alivio de pe- } \\
\text { nas y castigos, denuncias por excesos de autoridades. }\end{array}$ & 9 \\
\hline & $\begin{array}{l}\text { Solicitud de licencia absoluta para el marido, petición } \\
\text { de traslado del cónyuge militar, demanda de auxilio de } \\
\text { paga o pensión militar, petición de exención tributaria o }\end{array}$ & 14 \\
& limosna, reclamación de bienes confiscados. & \\
\hline $\begin{array}{l}\text { La salud y los } \\
\text { sentimientos }\end{array}$ & $\begin{array}{l}\text { Solicitud de licencia matrimonial y petición para atender } \\
\text { la salud del ser querido. }\end{array}$ & 3 \\
\hline
\end{tabular}

Fuente: elaboración propia a partir de las cartas citadas en este artículo.

Este trabajo se inscribe dentro de la corriente de la historia social (Díaz, 2015) y de la teoría de los estudios de género (Rodríguez e Ibarra, 2013), y se realizó a partir de un análisis crítico con base en el método cualitativo. Su elaboración

3 Sobre la participación de los sectores populares en las guerras de Independencia, véase Almario (2013) y Bonilla (2010).

4 Las transcripciones y publicaciones de cartas sobre mujeres en la Independencia de Colombia son en realidad bastante escasas. Solo habría que mencionar algunas cuantas intercaladas entre los voluminosos acervos epistolares publicados sobre los militares y gobernantes que contaron con poder de mano en este periodo, tales como la correspondencia del general Francisco de Paula Santander (Academia Colombiana de Historia, 1916) y la recopilación del edecán Daniel Florencio O'Leary (1983) sobre las cartas del general Simón Bolívar. No obstante, como trabajo reciente de epistolario de mujeres de la Nueva Granada y Venezuela, vale citar a Peralta y Quintero (2020). 
se llevó a cabo a partir de la consulta de fuentes documentales primarias, principalmente con la revisión de los legajos del Fondo Secretaría de Guerra de Marina de la sección República del Archivo General de la Nación. Esto implicó una minuciosa y paciente labor de búsqueda porque la proporción de las cartas escritas y firmadas por exponentes del género femenino durante estos años no llegaba a representar ni siquiera el $5 \%$ del total. Las pesquisas permitieron recopilar diferentes tipos de documentos: desde petitorios judiciales y juicios de infidencia hasta declaraciones, reclamaciones ${ }^{5}$, denuncias y cartas privadas.

El marco temporal de este estudio va desde los tiempos de la Primera República (1810-1815), pasa por la fase de la Reconquista española (1816-1819) hasta los años posteriores a la batalla de Boyacá del 7 de agosto de 1819 cuando se empezaron a sentar las bases definitivas del sistema republicano. Cabe aclarar que la mayor parte de la muestra utilizada en este trabajo corresponde a remitentes mujeres pertenecientes al bando republicano que elevaron sus peticiones en la última fase de la guerra.

En contraste con el formalismo de las cartas oficiales, se observa en estas misivas suscritas por mujeres un habla más coloquial. Pero principalmente se nota el sentimiento con el que exponen sus clamores, pues estos documentos son, además, un prisma a través del cual podemos adentrarnos en la vida social y cotidiana de este segmento de la sociedad que ha sido relegado por la historiografía nacional.

\section{Las mujeres en medio de la tensión política}

Debe tenerse en cuenta que las mujeres participaron de diversas formas durante las luchas de Independencia. Además de estar en el campo de batalla, algunos documentos de la época revelan cómo algunas de ellas sirvieron de guías, correos y auxiliadoras. Para la batalla del Alto Palacé ocurrida a finales de 1813, en la cual se impusieron militarmente los patriotas, fueron incorporadas diecisiete "voluntarias", algunas vestidas de hombre, por cuya razón varias de ellas murieron en combate (Gazeta Ministerial de Cundinamarca, 1814, p. 691).

Desde luego, ellas tampoco quedaron exentas del ambiente de radicalismos y tensiones, por lo que polarización entre republicanos y monárquicos. Alto fue el costo político que debieron pagar aquellas que fueron objeto de represión por sus férreas convicciones ideológicas o simplemente por ser las parejas sentimentales de esposos señalados por delitos de rebeldía o sedición. Otras

Para un completo estudio sobre los tipos de reclamaciones en la Independencia y la forma como los sectores populares recurrieron a ellas como práctica política y fórmula de negociación, véase Garrido (1993). Vale citar, además, el trabajo de Catalina Villegas (2006) sobre la mujer y la defensa de sus derechos. 
sacrificaron sus vidas en aras de su causa política; este es uno de los episodios más dramáticos de estas guerras por la emancipación ${ }^{6}$.

Resulta un tanto aventurado lanzar generalizaciones respecto a las tendencias regionales en torno a las adhesiones políticas de las mujeres a uno u otro partido, pues habría que referirse al contexto de cada zona y a cada momento específico. Sin embargo, es posible afirmar hipotéticamente que las provincias de Santa Marta, Popayán y especialmente Pasto fueron las más propensas a manifestar su fidelidad a las banderas del rey, territorios en los que precisamente la resistencia realista fue más arraigada. Entre tanto, la causa republicana fue ganando paulatinamente más adeptas, y ese sentimiento se esparció desde la zona andina central y nororiental de Colombia.

Son innumerables los ejemplos en los que se evidencia el impacto de las retaliaciones políticas, especialmente durante la fase de la Reconquista española, a través de interrogatorios, cárceles, fusilamientos, confiscaciones y destierros de las cabezas más visibles del movimiento revolucionario. Para ello, fueron instituidos tres tribunales: el Consejo de Guerra, el Consejo de Purificación y la Junta de Secuestros?.

A principios de julio de 1816 en la ciudad de Santa Fe (Bogotá), la señora Mariana Duarte intercedió por su hija ante las autoridades de la Reconquista para que le fuera levantada la orden de destierro ante las sospechas sobre su conducta política:

Excelentísimo señor:

Doña Mariana Duarte y González, prestando voz y caución por mi hija doña María Regina Miranda ante V. M. según derecho y con el debido respeto digo que a efecto de acreditar la buena conducta y arreglado proceder de mi hija en el tiempo de la insurrección, se ha de servir V. M. mandar que el actual escribano proceda a practicar la información; y que los testigos que presentaré declaren al tenor del interrogatorio siguiente:

$1^{\text {a }}$. Si conocen a la referida mi hija y si les tocan las generales.

$2^{\mathrm{a}}$. Si saben cuál ha sido su conducta en todo el tiempo de la insurrección; cuál su modo de pensar y si tiene nota que la haga odiosa en la sociedad.

$3^{\text {a }}$. Si saben si su carácter, honradez y natural moderación la hace incapaz de mezclarse en tumultos y partidos.

$4^{\mathrm{a}}$. Si saben que se ha hecho acreedora por lo mismo de la estimación de todos los hombres de bien y realistas. Lo que practicado se ha de servir vuestra merced

Según cálculos hechos por algunos historiadores, se cree que aproximadamente cincuenta y nueve mujeres fueron llevadas al patíbulo (Rodríguez, 2010, p. 5).

$7 \quad$ Sobre esta fase de la Independencia, véase el reciente trabajo de Gutiérrez (2016). 
mandar se me entregue original para los usos que me convengan que siendo justicia a V. M. suplico provea como solicito. (Duarte, 1816)

Pocos días después, en esta misma capital, otra desterrada de nombre María Riveros se lamentó de las complicaciones económicas padecidas tras la suspensión de su oficio de vendedora. Adujo no haberse inmiscuido en tumultos ni escándalos y que no había tenido ningún trato con el "insurgente" Simón Bolívar:

Señor gobernador político y militar:

María Riveros, vecina de esta capital, ante V. S. con mi acostumbrado respeto, y como más haya lugar en derecho parezco por medio de este y digo: que con el motivo de haberse por mi situación pobre sujetada a la plaza, que es la negociación de que subsisto con mi pobre familia, y este balance lo emprendí después de la entrada en esta ciudad del Bolívar, que antes no lo ejercía. Con este motivo se me dio pasaporte para que siguiese al pueblo de Bogotá ${ }^{8}$, donde me hallo; y sin embargo de haber sido la última a quien se dio el pasaporte, fui la primera que obedecía esta superior orden. Yo aunque me ejercitaba en el balance de vender, jamás me he mezclado en otras cosas, y mi conducta ha sido siempre irreprensible, como lo puede declarar el mismo capitán de la plaza, y caso necesario lo acreditaré con testigos fidedignos. En esta segura inteligencia ocurro a la bondad de V. S. suplicándole que por un efecto de sus notorias beneficencias se digne alzarme el destierro, para volver a residir en esa ciudad, como lugar de mi vecindario seguro de que jamás se arrepentirá V. S. de haber hecho esta obra de caridad, por la que tendré la satisfacción de que será uno de los escogidos para con Dios, a quien pido guarde la importante vida de V. S. muchos años. (Riveros, 1816)

En el marco de la guerra, el espionaje fue fuertemente perseguido por los dos bandos en contienda. Es ampliamente conocida la labor realizada por Policarpa Salavarrieta (Montoya, 1972) quien pagó en el patíbulo su colaboración con las guerrillas patriotas que se organizaban en 1818 y 1819. El caso que se describe a continuación compromete a Josefa Algarra, una mujer de la ciudad de Bogotá, que pidió a principios de 1813 que se le permitiera volver a su domicilio luego de haber sido acusada ella y su cónyuge de recibir unas cartas enviadas por su hijo, las cuales fueron descubiertas camufladas en un bordón.

Excelentísimo señor:

No he salido de esta capital, ni tampoco mi marido don Manuel Triana, como Vuestra Excelencia se sirvió prevenírnoslo en providencia de veinte y tres de diciembre último, que se nos intimó por el escribano don Vicente de Rojas; hemos por consiguiente ciegamente obedecido el mandato de Vuestra Excelencia, que estimando que en el estado en que se hallan los negocios de esta provincia, puedo ya restituirme a mi casa a cuidar de ella y de mis hijos; cuyo desamparo recomiendo al compasivo pecho de Vuestra Excelencia, y no menos de las aflicciones y perjuicios que hemos padecido sin culpa alguna, como está acreditado en el respectivo

$8 \quad$ Hoy municipio de Funza. 
expediente. Espero de la justificación de Vuestra Excelencia tenga la bondad de levantarnos el decreto impuesto en la citada providencia o por lo menos a mí, a los fines expuestos, y en su consecuencia mandar que para que en Zipaquirá no se nos incomode con vejaciones, ni insultos, ni otro modo alguno, se expidan a aquellos jueces las órdenes necesarias, como dispuso el Tribunal de Vigilancia y Seguridad en la sentencia que pronunció en el citado expediente, que confirmó la Junta de Gobierno; y que para nuestra mayor seguridad se nos dé pasaporte, con el cual podamos transitar libremente al pasar de nuestro domicilio, como lo exigen la razón y la justicia, que espera de la piedad de Vuestra Excelencia. (Algarra, 1813)

En respuesta a este clamor, el 20 de enero el tribunal decidió revocarle a Josefa la restricción bajo la condición de que se comportara con "juicio y moderación".

En medio del juego de retaliaciones políticas y de la tensión militar de la época, las mujeres no dudaron tampoco en elevar su voz al ver que se estaba cometiendo algún exceso o procedimiento indebido contra sus seres queridos, medidas excepcionales que podían traer consigo otro tipo de repercusiones como, por ejemplo, dejarlas a ellas y a sus familias en estado de desamparo. Sobre este tipo de problemática, esta fue la solicitud formulada en 1820 por la ciudadana Natividad Rodríguez desde la parroquia de San Cayetano ante la captura de que había sido objeto su esposo Manuel Carvajal:

el día de ayer que contábamos dos del corriente julio fue a aquella parroquia el oficial Rafael Matamoros del batallón de Pamplona que manda el comandante Heras y estando el citado mi marido expendiendo el aguardiente en aquel estanquillo por recomendación del ciudadano Marcelino Ordóñez, fue el citado Matamoros y sin darle mi marido un motivo, ni haberlo habido antes en manera alguna, arrebató con él y se lo llevó dejándome a mí pobre y desamparada con una niña de pechos sin tener a quien volver mis ojos que socorra mis necesidades pues aunque tengo padre vivo, se halla enteramente ciego. (Rodríguez, 1820)

En los inicios de la Segunda República, fue publicado en noviembre de 1819 por el vicepresidente Francisco de Paula Santander un reglamento dirigido a combatir los desmesurados niveles de deserción en la tropa. Allí se estableció que cualquier persona que abrigara, ocultara o auxiliara a un fugado, sufriría la misma pena dispuesta por las Ordenanzas, es decir, debía ser sometida a la justicia militar (Santander, 1819, p. 1). En el desespero de los desertores por buscar algún escondite seguro, algunas mujeres se vieron directa o indirectamente involucradas.

Esta fue la defensa esgrimida en noviembre de 1820 por María Josefa Herrera ante las autoridades republicanas en reacción a los señalamientos en su contra por aparentemente haber protegido, ella y su familia, a dos desertores del Ejército Libertador: 


\section{Excelentísimo señor:}

María Josefa Herrera, vecina de Ibagué, ante Vuestra Excelencia, con el más debido acatamiento y respeto, digo: que el sábado cuatro del corriente (hallándonos yo y mi marido ausentes), llegaron dos desertores chiguanos a nuestra posada a donde se mantuvieron con seis hijos que tenemos (ignorándolo mi marido y yo) hasta el martes siete en que llegué yo por la noche, y luego que los vi, y teniendo sospechas de que tales podrían ser desertores, les dije que se huyeran, que se marcharan, que yo no los conocía ni quería tener disgusto con mi marido, ni quería verme en enredos ni trabajos, que bastante tenía yo con mis hijos y pobreza; y estos luego al punto se fueron (al parecer) y los vecinos que por allí cerca habían tenido noticia de los tales desertores, dieron luego al punto aviso al ciudadano Fermín Pardo, vecino de Chiguachi, que inmediatamente juntó gente y fue a buscarlos. Mi marido José Joaquín Bonilla llegó el miércoles ocho del corriente como al mediodía y, estando dicho mi marido tomando el sustento, llegó mi hijo Esteban (que venía de pastorear unas ovejas que tenemos recomendadas) y dijo a su padre y juntamente a mí que acababa de ver a los dos mozos que habían arrimado allí; es decir, los tales desertores [...] luego al punto se aparecen el mencionado Fermín Pardo con gente y solicitando por las inmediaciones de la posada a los dichos desertores, encuentran al mismo mi hijo ya mencionado y lo prenden llevándolo amarrado a pesar de los gritos que daba mi marido a la novedad, y en vez de estos declararse con él, lo ultrajan bien de palabras y de hechos, hasta que por último dijeron que habían de entregar los desertores que tenía escondidos, que a dónde estaban. Comprendido ya el motivo de aquella tropelía, como no hacía mucho que los había descubierto a donde estaban escondidos, no hubo embarazo en que dicho mi hijo y mi marido dijeran a dónde se hallaban. He aquí de donde resulta que por aquella casualidad quieran precisamente acumular la complicidad a nuestra familia y hacer causar una total ruina a esta desvalida familia.

Resulta pues que mi marido como hombre pusilánime y sin razones para poderse explicar, se halla fugitivo y a mí me llevaron presa con dos de mis hijas, y todos mis hijos tiernos se hallan abandonados [...] de donde me he venido fugitiva con dichos mis hijos a postrarme a los pies de Vuestra Excelencia, pidiéndole por Dios que lo proteja con lágrimas de mis ojos como a un padre único que ampara, defiende y protege, se digne de amparar a los desvalidos de esta desgracia, declarándome a mí y a mi marido libres de toda prisión y pena (pues lo somos de la culpa por ante la presencia de Dios) para que podamos nuevamente unirnos y vivir tranquilamente en el servicio de Dios y en el cumplimiento de nuestras obligaciones que así Dios les debe favorecer y ayudar. (Herrera, 1820)

El caso fue remitido a Bogotá, pero del fallo final no quedó ninguna información en el expediente.

En noviembre de 1819 un grupo de damas oriundas de la ciudad de Girón clamaron compasión tras haber sido conminadas al destierro por ser esposas de seguidores del antiguo régimen monárquico. En consonancia con esto, no vacilaron en pedir se contemplará la posibilidad de pagar una fianza para librarse de este castigo: 
Excelentísimo Señor presidente del Estado y capitán general de los ejércitos de Venezuela y Nueva Granada:

Cuando Girón tuvo la mayor dicha en conocer la digna persona de Vuestra Excelencia aclamado por todos los pueblos, recientemente por el triunfo de Boyacá; tocó a nosotras la desgracia de que algún influjo obre para que Vuestra Excelencia ordenase al alcalde ordinario de primer voto de esta ciudad nos intimase destierro de este nuestro patrio suelo a ajenos países, talvez o por mujeres de los emigrados a la provincia de Cartagena $u$ otras, y porque se creyese que el sentimiento de nuestras familias nos hiciese desear el gobierno español, y que con este motivo difundiésemos especies o noticias subversivas a la República, siéndonos moralmente imposible la comunicación con aquellos mismos. Vuestra Excelencia sabe muy bien que las mujeres en el sistema actual han sido reputadas como un cero en lo político, que debe saber que las que representan son las más de ellas mujeres que solo han adquirido de sus padres una sana y cristiana educación, pero nada de máximas políticas ni sabias, pues el cantón de Girón siempre se ha compuesto de vecinos campesinos ocupados en la agricultura, pero sin profesar otro arte que los distinga entre los hombres. Somos pobres, llenas de hijos y actualmente en escasez suma. Amamos el gobierno liberal, desengañadas de la opresión y violencia ejecutadas por los bárbaros opresores de la Libertad. Nos comprometemos a dar al diputado de Vuestra Excelencia una fianza capaz de responder de nuestra conducta política. Así es que suplicamos a Vuestra Excelencia que en uso de las funciones de su bondadoso corazón se digne recovar el primer mandamiento pronunciado en catorce de octubre pasado, y ya también el que posteriormente nos ha intimado el señor gobernador de Occidente. De este modo enjugará Vuestra Excelencia las lágrimas de unas infelices desterradas y las de sus familias y de este modo manifestará al orbe entero que no teniendo de nosotras culpabilidad en la emigración de nuestros consortes, nos repute inocentes pues hasta ahora no se ha visto que mujer alguna en tiempos de revolución ataje los ímpetus del capricho y mal pensar de sus maridos.

Dios nuestro señor guarde a Vuestra Excelencia muchos años para aumento y prosperidad de la República. Sitio de Los Santos, noviembre $1^{\circ}$ de 1819.

Gertrudis Calderón, María Entralgo, Rosalía Calderón, María Paz Calderón, Isabel Perea, Paula Calderón. (Calderón, 1819)

Cuando el oficial patriota Antonio Obando llegó a la provincia del Cauca encontró un panorama absolutamente desconcertante no solo por el desorden reinante, sino por el estado de devastación producido por los realistas que desde los inicios del periodo revolucionario habían fijado una férrea resistencia en estas tierras del sur de Colombia. Muchos habían migrado y abandonado sus casas. Así se refirió Obando en una carta enviada el noviembre de 1819 al general Santander, en la cual mostraba su enfado por la actitud traicionera y desleal de las mujeres de Popayán:

Espero me dé órdenes para ahorcar mujeres, pues aquí no ha quedado más que este género, y tan malditas, que son las que nos hacen la guerra; cuando menos piense tiene allá unas doscientas que he de remitir para que las mande a los Llanos [Orientales] a poblar. (Cortázar, 1969, p. 127) 
Dos años más tarde, el coronel patriota José Concha seguía lamentándose del poco apoyo popular recibido en esta región:

Los pueblos de Patía y el de Popayán son iguales; muy pocos los patriotas y estos en esta vez, según dice el general, no se han querido comprometer. El que no se ha ido huyendo se ha ocultado en la misma ciudad, y vive muy tranquilo fuera de las trincheras, y la mayor parte, principalmente mujeres pulperas, dan parte al enemigo y mantienen una comunicación tirada. Dentro de las trincheras viven las tropas. (Cortázar, 1969, p. 476)

A principios de agosto mandó enviar las mujeres espías "más perversas" a Cali pero, según dijo, "sería necesario sacar todo el pueblo bajo, principalmente las mujeres" (Cortázar, 1969, p. 483).

Los crecientes gastos que implicaba el sostenimiento de los ejércitos obligaban a sus comandantes y a las autoridades militares, políticas e incluso eclesiásticas a pedir el apoyo de la comunidad, ya fuera a través de donativos voluntarios o, en otras ocasiones, con cuotas impuestas a la fuerza y con amenazas de retaliación.

Vale traer a colación el caso de un grupo de mujeres oriundas de la Villa del Socorro que dieron muestras, a principios de 1820, de su adhesión al sentimiento patriótico. El gobernador y comandante de esta villa, don Antonio Morales, reportó detalladamente al vicepresidente Santander sobre el comportamiento de las damas de esta localidad. Cada señora proveía de comida en su casa a un soldado, quien a su vez le colaboraba en sencillos oficios domésticos y, además, asistía diariamente a las jornadas de instrucción y al servicio de la guarnición; y de noche dormían en el cuartel. De esta manera, el Estado veía aliviar un poco sus finanzas en esos momentos de escasez. Morales se comprometió a disciplinar prontamente en la provincia un grupo de trescientos hombres con la esperanza de que las damas de San Gil y Vélez contribuirían de igual forma al sostenimiento de las tropas. Adicionalmente, le pidió a Santander incluir en la Gaceta ministerial el "rasgo patriótico" de estas damas para que sirviera de precedente y estímulo a los demás pueblos (Cortázar, 1969, p. 232).

Ellas también buscaron la forma de manifestar sus sentimientos políticos y, en un emotivo mensaje, hicieron saber al alto estamento militar su disposición incondicional de apoyo:

Héroe singular

Si las matronas de Roma sacrificaron sus alhajas para conservar la libertad que les había dado Bruto: las ciudadanas del Socorro sacrificarán hasta su sangre para sostener la que deben al eterno sublime del Inmortal Bolívar. Las expresiones con que el héroe de Colombia favorece al sexo del Socorro, son tan gratas a nuestro corazón como la libertad misma. Tanto honor no cabe sino en la mano de quien es 
más grande que Ciro y Alexandro. Callamos y depositamos las lágrimas de nuestro reconocimiento en el seno del Libertador y padre de la patria. Aprenderemos a merecer sus elogios imitando sus virtudes.

Socorro, febrero 25 de 1820.

Rosa Delgadillo, Pila Villarreal, Ignacia Villarreal, Apolinar Frana, Josefa Beriña, Rosa Sobrino, Petronila Plata, Salomé Plata, Nicomedes Plata, Rosa Montero, Cruz Montero, Antonio Monsalve, Dionisia Monsalve, Teresa Amaya, Ignacia Ardila, Antonia Amaya, Paula Amaya, María Rengifo, Dorotea Rengifo, Bárbara Acevedo, Micaela Gómez, Manuela Villar, María Leonor Gómez. (Delgadillo, 1820)

\section{Esta carta suscitó de inmediato una emotiva respuesta por parte del coman- dante del cuartel general del Socorro:}

A las ilustres matronas del Socorro:

Un pueblo que ha producido mujeres varoniles, ninguna potestad humana escapa de subyugarlo. Vosotras hijas del Socorro vais a ser el escollo de vuestros opresores. Ellos en su frenético furor profanaron lo más sagrado, lo más inocente, lo más hermoso de esta especie; os hollaron. Vosotras habéis realzado vuestra dignidad endureciendo vuestro tierno corazón bajo los golpes de los crueles.

Heroicas socorreñas: las madres de Esparta no preguntaban por la vida de sus hijos sino por la victoria de su patria. Las de Roma contemplaron con placer las gloriosas heridas de sus deudos y los estimulaban a alcanzar el honor de expirar en los combates. Más sublimes vosotras en vuestro generoso Patriotismo, habéis empañado la lanza, os habéis colocado en las filas y pedís morir por la Patria. Madres, esposas, hermanas, quien podrá seguir vuestras huellas en la carrera del [f. 350v] Heroísmo. ¿Habrá hombres dignos de vosotras? No! No! No! Pero vosotras sois dignas de la admiración del universo y de la adoración de los libertadores de Colombia.

Cuartel General en el Socorro a 25 de febrero de 1820. (Morales, 1820)

En una guerra cruda y prolongada era altamente probable que se registraran algunos excesos y arbitrariedades de las cuales no se libraron las mujeres ${ }^{9}$. La siguiente es una valiente denuncia expuesta por una vecina de Popayán al general Bolívar en su paso por esta disputada ciudad del sur, en la que se sindica al gobernador de abusar de su hija:

Excelentísimo señor Libertador:

Teresa Lazo, vecina de esta ciudad, ante Vuestra Excelencia por medio de este memorial digo: que nada es más cierto que el que los clamores de los infelices tienen toda aceptación ante la divinidad. Ella ha puesto la justicia (su mejor atributo) en manos de Vuestra Excelencia para vengar sus agravios. Ella, no sin designio, ha escogido a Vuestra Excelencia para que ejercite las funciones de Dios en la Tierra

Aparte del caso que se reporta, existió otro episodio parecido en agosto de 1821 tras la denuncia del gobernador español de Cartagena, don Gabriel de Torres, tras los excesos cometidos por militares republicanos contra algunas mujeres que huían de la sitiada plaza de Cartagena (Corrales, 1883, p. 254). 
[...]. Me hallo ofendida, excelentísimo señor, en la persona de una hija doncella víctima inocente [en] sus pocos años.

El señor gobernador de esta provincia, coronel José Concha, en el mes pasado de junio del año anterior, por fines tan vergonzosos como increíbles en la persona de un magistrado, pretexta que soy una mujer adicta al sistema español y acaso perjudicial al republicano; y me hace conducir con escándalo a un cuartel, en unión de mi hija Rafaela como delincuentes [...] entonces, aprovechándose de las sombras de la noche y de la calma con que el hombre se entrega al sueño, se me presentan en la prisión los dos oficiales Martínez y Guerra a las doce de la noche y sacan de mis brazos a mi desgraciada hija, con el objeto supuesto de tomarle una declaración. Presentada al señor Concha fue el resultado el que va a oír Vuestra Excelencia con horror. Se queda solo con ella, saca el sable, se lo pone a la garganta, la amenaza espantosamente con las expresiones más denigrantes, la intimida, la enajena de sí misma y mi hija es violada, estuprada y perdida.

[...] Mi hija, entre el dolor y el llanto no puede ocultarme la violencia y su desgracia. La sensibilidad de madre, la iniquidad perpetrada a favor del desenfreno lascivo y el verme para esto encarcelada, me hicieron producir algunas expresiones que dieron trascendencia del hecho en la ciudad. Un abismo, señor, trae otro. Para que absolutamente no se hiciese público, y para que el oprobio y el de mi hija quedase sepultado, tomó el violento partido del destierro, y al momento nos sacaron a pie, llenas de angustias, de trabajos y miserias hasta el puerto de Buenaventura a que nos destinaron con el objeto seguramente de que muriésemos para triunfar del crimen [...]. Por el destierro, señor, perdió mi familia sus pocos recursos, las alhajas de uso se las han robado, y la miseria acaba de sellar nuestras desgracias [...]. Soy mujer, señor, e infeliz. Yo no puedo luchar con un poderoso. En las manos de Vuestra Excelencia pongo mi justicia.

Popayán, febrero 7 de 1822.

Teresa Lazo (Fundación John Boulton, 1960, pp. 265-266).

Bolívar ordenó adelantar las investigaciones con el fin de esclarecer los hechos y aplicar los castigos correspondientes.

\section{Las mujeres ante las penurias económicas}

La nota predominante durante el período de Independencia en materia económica fue la situación de crisis en prácticamente todos los sectores. La guerra fue sin duda el factor que acentuó el deterioro productivo y fiscal que venía experimentándose desde finales del siglo XVIII (Kalmanovitz, 2008, pp. 10-22). Evidente fue el impacto social de esta desaceleración de la economía, especialmente en los sectores sociales más vulnerables.

No hay duda de que el mayor lamento expuesto por las mujeres durante estos tiempos de guerra fue su maltrecha situación económica y así lo constata la muestra de cartas seleccionadas, de las cuales al menos el 50 \% hacían alusión a 
esta problemática. Las migraciones y las órdenes de reclutamiento que recaían sobre sus esposos e hijos significaban para ellas un gran reto porque no solo tenían que explorar fórmulas de subsistencia para ellas, sino para sus hijos y demás familiares que quedaban a su cargo. Las dificultades tendían a empeorar cuando las afectadas no tenían ninguna otra opción de ayuda cercana o cuando eran de avanzada edad o estaban afectadas por enfermedades.

Ante esta situación, una de las primeras reacciones consistió en elevar peticiones para el traslado o el trámite de licencias definitivas de sus esposos o hijos militares con miras a tenerlos nuevamente cerca de sus hogares y así apaciguar un poco las crecientes cargas económicas. Cabe precisar por anticipado que la respuesta de la autoridad militar y política varió según cada circunstancia.

En mayo de 1820 una vecina oriunda de la ciudad de Girón se dirigió directamente al general Bolívar en busca del otorgamiento de la licencia absoluta para su marido. Con miras a imprimirle más fuerza a su petición, que fue aprobada en su momento, ella puso de presente los auxilios prestados a la tropa patriota:

Excelentísimo señor presidente de la República de Colombia, Simón Bolívar:

Señor: Ninfa González, mujer legítima de Gregorio Reyes, representa a Vuestra Excelencia la dura y falta situación a que se halla reducida, enferma, rodeada de seis hijas pequeñas y sin recursos algunos para mantenerlas. Este cuadro lastimoso de miserias en que se ve hoy sumergida mi casa, después de una serie continuada de trabajos por los godos, ya en las cárceles, ya mendigando, tal vez el sustento con que socorrerlo y alimentarlo en aquella época, serán un motivo de mi justa solicitud para que condolido del peso de mi desgracias, le conceda a mi marido, el retiro a su casa o la licencia absoluta para que proporcione a su crecida familia el sustento o cuando no un destino en esta donde podrá ser útil al Estado y a sus hijas. Pero si los antecedentes motivos no son bastantes, sean al menos los servicios que en mi anterior representación dirigida a Santa Fe referí a Vuestra Excelencia, en ella expongo la del fomento de una compañía que entregó vestida, armada y equipada, que hoy se halla agregada al batallón de Vargas, los que haya contraído en el puerto de Ocaña donde abordó primero que ninguno de cuyo resultado se le nombró ayudante mayor de aquella división, y finalmente los de su hermano fray Cayetano Reyes, capellán en la expedición del Sur, los de su otro hermano Baltasar, muerto en la funesta acción de La Puerta de los del quinto de Pamplona; el hambre, la desnudez en que me hallo, mi achaque y la necesidad de que sus hijas tengan un protector que las eduque e impida que la indigencia quebrante las márgenes de su honestidad, son la más relevante causa que mueve mi corazón a solicitar esta gracia que imploro de Vuestra Excelencia como acostumbrado a ejercerla en favor de los infelices que justamente las solicitan; ella será el fomento de nuestra santa causa y su magnanimidad extendida por la faz de la tierra, se eternizará su nombre, elevará al rango de los más grandes héroes y será en fin el único que termine nuestras calamidades.

Dios guarde a Vuestra Excelencia muchos años.

Girón, mayo 3 de 1820. (González, 1820) 
A Ignacia Alfonsa, mujer adulta mayor y avecindada en el pueblo de Fontibón en los alrededores de la ciudad de Bogotá, le fue negada por esos mismos días una solicitud a través de la cual aspiraba a que su único hijo reclutado en el batallón de esta capital fuera licenciado del servicio para que le ayudara a amortiguar sus afugias económicas. De nada le sirvió haber expuesto una serie de servicios y sacrificios rendidos por su familia a la causa patriótica ni tampoco le valió el haber ofrecido otro hombre como reemplazo a su ser amado en la milicia:

hallándose mi único hijo Eustaquio Acero de soldado en el batallón de su mando; no puedo menos que hacer presente a usted que este es el único hijo que me sostenía en mi ancianidad y extremada miseria a que me hallo constituida, sin que en el día pueda verificarlo a causa de su continua tarea en la carrera militar. Por otra parte, mi legítimo esposo se halla igualmente en una avanzada edad y absolutamente enfermo e imposibilitado para buscar el diario sustento que tan preciso y necesario es para socorrer nuestra indigencia. También manifiesto a usted que otro de los hijos que ayudaba a socorrernos siguió en expedición para el Sur en servicio de nuestra justa causa. Por todas estas razones me hallo precisada a suplicar a usted se digne en mérito de lo relacionado conceder el que se licencie el citado mi hijo, libertándolo del actual servicio, ofreciéndome en tal caso a poner en su lugar otro hombre que pueda desempeñar las funciones militares, pues de otro modo quedaremos arruinados sin auxilio alguno y en la precisión de perecer arrollados de las calamidades que nos rodean. (Alfonsa, 1820)

Respuesta negativa recibió también al mes siguiente María Beltrán, vecina de Nemocón y madre de otro soldado reclutado en el regimiento de la capital, pese a haber argumentado que no tenía cómo alimentar a sus cuatro hijas, una de ellas tullida (Beltrán, 1820)

Al cuartel general del Libertador Simón Bolívar, ubicado en la villa del Rosario en la frontera con Venezuela, llegó otra carta escrita por la ciudadana Francisca Losada quien abogó por el pronto regreso de su sobrino, el único que podía responder por ella a tan avanzada edad:

mi sobrino Ciervo de Dios Guevara, impelido del ardor de servir a la patria, rentó plaza de aspirante sin mi permiso (por hallarse bajo mi tutela) en el batallón Barcelona. A poco tiempo, siguió para el norte quedándose en Pamplona por haber enfermado gravemente. Con la muerte de mi hermano el ciudadano don Ignacio Losada que murió en el destierro que decretó contra él el gobierno español por su adhesión a la causa de América, quedé en absoluto desamparo, miseria y enfermedades, de que adolezco todavía. En medio de este conflicto, no me quedaba otro apoyo que este joven que creía sería el báculo de mi vejez y en quien recayese los derechos de varias capellanías que aquel obtenía, con cuyos réditos me mantenía. A fin de disfrutar de estos cortos emolumentos, he practicado varias diligencias con el objeto de tener a mi lado a dicho mi sobrino, solicitando el pase de aquel cuerpo a otro de los de esta ciudad de Bogotá. Pero hasta la fecha han sido infructuosos todos mis pasos. El señor general Plaza (que fue a quien me dirigí) me acaba de contestar que él no está facultado para conceder esta licencia y dice que ocurra a 
Vuestra Excelencia como jefe supremo del Ejército. En esta atención y en el concepto de que Vuestra Excelencia es el amparo de las huérfanas que siempre han mirado con ojos compasivos a todas aquellas familias que padecieron por el gobierno tiránico, ocurro rendidamente a su superioridad a fin de que se digne otorgarme esta gracia. (Losada, 1820)

En la carta transcrita a continuación, la afectada era una esposa que veía cómo su marido era remitido a combatir de un extremo a otro mientras ella debía valerse de peripecias para alimentar a sus dos pequeños. El llamado angustiante era a que se le permitiera a este conscripto retornar al seno de su hogar para cumplir con sus deberes maritales.

Excelentísimo señor:

Josefa Arce, conjunta persona de Bernardino Burgos, vecino de Honda, ante Vuestra Excelencia con el mayor respeto parezco y digo: que hace el espacio de dos años que mi consorte sirve en la carrera de las armas republicanas, unas veces ausente en el sitio opuesto a la plaza de Cartagena, y otras al lado del sur, a oponerse al enemigo y hacer la justa defensa de nuestros derechos, todo esto me es muy agradable. Pero sí he experimentado yo y dos tiernos hijos que tengo a mi lado una estación calamitosa y notorias necesidades, sin más auxilio que el de la divina providencia, en términos que he mendigado bajo de estas consideraciones, suplico a la bondad de Vuestra Excelencia que inclinándola como acostumbra, se digne concederle su licencia absoluta para poder buscar la subsistencia de sus precisas obligaciones y cumplir al mismo tiempo con el estado matrimonial, por lo que implorando justicia ella mediante.

A Vuestra Excelencia suplico reverentemente provea como pido en lo necesario. (Arce, 1820)

El vicepresidente Santander fue muy enfático en dictaminar el 11 septiembre de 1821 que era preciso determinar si Bernardino era inútil para el servicio porque, de lo contrario, debía seguir en las filas.

En el caso que se examina a continuación, la solución que planteaba Gregoria Garzona en una carta privada remitida a su esposo no era el otorgamiento de la licencia absoluta, sino la posibilidad de que estuviese más cerca de los suyos:

Bogotá, 8 de octubre de 1821.

Estimado esposo Salvador Bastidas: aunque sin ninguna [carta] tuya a que contestar, hago esta con el objeto de decirte que me hallo en la más lamentable situación que se piense, con una enfermedad tan grave que no pienso otra cosa sino es ya el morir y para esto tener dos hijos los que mantengo sobre lo imposible y pienso que si muero quedarán a la inclemencia por lo que te pido encarecidamente que te empeñes cuanto pudieres por venir a ver a tu pobre mujer. No lo hagas por mí, hazlo si quiera por tus hijos que no tienen otro anhelo sino su padre; me parece que en dos años que hace que carezco de vista tengo razón para quejarme y así no me 
dejarás esperando porque quizás será ya la última vista. Y si lo determinas que sea lo más pronto y me contestas en el correo del 15, pues no aguardo otra cosa porque ni hay qué vender ni qué ponerme porque donde me han fiado ya no quieren fiar más, y así espero vengas a socorrer mis necesidades y es cuento tengo que decirte. Yo me alegraré que estés bueno y que te hayas divertido bien que yo acá también me divierto con mis males cumpliendo la voluntad de Dios a quien pido te guarde muchos años. Tu verdadera esposa que de veras te ama y desea ver. (Garzona, 1821)

Bastidas se hallaba en ese momento en el depósito de reserva de la ciudad de Honda y allí presentó ante el gobernador y comandante general esta misiva como prueba incontestable de la crítica coyuntura de su amada y en solicitud de que fuese trasladado a Bogotá para estar al pie de su desguarnecida familia. La petición fue negada. Ante esta negación, Bastidas recurrió al vicepresidente Santander, quien finalmente le otorgó el permiso con la condición de que prestara sus servicios en el cuerpo de artillería.

La tunjana Josefa Araos, viuda del ciudadano Joaquín Umaña, pidió afanosamente a finales de febrero de 1820 el retorno de uno de sus dos hijos que mantenían operaciones en territorio venezolano:

deseando dar el mejor testimonio de mi adhesión y amor por la Patria, presenté a Vuestra Excelencia a mis dos hijos Joaquín y Juan de Umaña, los que hacían mi único apoyo en la triste situación, orfandad y miseria a que fui reducida por los españoles habiendo fusilado a mi marido y avocándose sobre los únicos bienes que hacían la subsistencia de mi dilatada familia. Mis dedicados hijos, queriendo cooperar con sus personales sacrificios a la consolidación del sistema, marcharon gustosos a las órdenes del general [Carlos] Soublette, y habiéndose alejado tanto que por sus últimas cartas sé que se hallan en la isla de Achaguas desde donde es casi imposible puedan subvenir de algún modo a mi grande pobreza y escasez. Persuadida de la generosidad que caracteriza el benéfico y compasivo corazón de Vuestra Excelencia, le suplico del modo más encarecido que impartiendo su beneficencia a esta pobre y afligida viuda, me conceda la gracia que mi hijo Joaquín venga a servir a uno de los Ejércitos que obran en la Nueva Granada. Así lo espero de Vuestra Excelencia que ha venido a enjugar las lágrimas de los infelices. (Araos, 1820)

María Josefa Pino abrigaba también la esperanza de que su esposo, después de haber dado muestras irrefutables de fidelidad al régimen republicano y de haber padecido los rigores de la migración forzosa por causa de la represión política, se le autorizara el traslado para estar más cerca de ella y así cumplir a cabalidad con sus obligaciones conyugales. De ese tenor fue su carta fechada el 27 de abril de 1820 desde la ciudad de Ibagué:

A consecuencia de la irrupción que hizo el enemigo en el Valle del Cauca, tuve que abandonar mi patrio suelo acompañada de mi esposo ciudadano Camilo Acuña y un tierno hijito. Todo lo renunciamos por seguir las armas de la República y buscar un asilo entre nuestros hermanos de Colombia, arrostrando para ello los rigores de un penoso tránsito del hambre y de la desnudez. A nuestra llegada a esta se promulga 
un auto por el señor gobernador ciudadano José Concha previniendo la presentación de todos los emigrados. Mi marido lo verificó inmediatamente y fue destinado al servicio de las armas como un soldado. Él se había prestado oficiosamente en dicho Valle al cumplimiento de este deber, distinguido con el carácter de sargento primero de milicias, yendo en auxilio del capitán Gutiérrez a la Vega de Supía en persecución de Mendiguren y sus tropas, que después condujo prisioneros a la de Cartago [...] Él en fin desempeñó honrosamente cuantas comisiones se le encomendaron por el teniente Juan Agustín Doncel para reclutar hombres en la ciudad de Toro; y ahora del modo que he expresado se le ha hecho marchar por la vía de La Plata, dejándome sola, abandonada en país extraño, en la mayor miseria por nuestra notoria pobreza, sin auxilios, sin recursos y sin arbitrio alguno para subsistir y ponerme a cubierto de la mendicidad [...] Dirijo mis clamores suplicándole sumisamente ordene el que se me restituya a mi caro esposo, quien podrá de este modo, sin abandonar las obligaciones conyugales, cumplir en nuestro territorio con las que impone la Patria en defensa de sus sagrados derechos. (Pino, 1820)

La otra opción con la que contaron las mujeres abandonadas o relegadas en el olvido era clamar por auxilios o por el otorgamiento de medios sueldos o pensiones militares. Ante un inesperado traslado de su marido, sargento integrado al Ejército Libertador que intentaba la liberación definitiva de la ciudad de Pasto, la señora Merced María Collazos pidió a las autoridades que le fuera cedida la media paga y se estudiara, además, la posibilidad de que él pudiera ser ascendido como reconocimiento a su trayectoria:

\section{Excelentísimo señor:}

Señor: si los trabajos y necesidades que he sufrido en los años pasados por el desamparo en que me he visto con mi familia en tierra ajena por ser la de Cali el lugar de mi nacimiento, no hubieran sido tan excesivas dimanadas de la ausencia de mi marido Antonio Santacruz por hallarse al presente sargento primero de brigada del batallón de Vargas y en el servicio de las armas a favor de la República de once años a esta parte, no molestaría la atención y respeto de Vuestra Excelencia suplicándole como rendidamente lo hago, y con todo encarecimiento: que doliéndose de mi orfandad y ningunos auxilios con que me hallo, sin padres, hermanos, ni parientes algunos a quien volver mis ojos, me hago el bien y caridad de socorrerme con la mitad del sueldo que se le tiene asignado al citado mi marido, para con ello poderme mantener con mi familia, inter se restituye a esta ciudad, por haber seguido el día de ayer con su cuerpo hacia Pasto; y que asimismo se sirva la bien notoria y acreditada justificación de Vuestra Excelencia darle el premio de ascenso que corresponda a sus servicios y méritos que ha contraído en el tiempo que hace sirve con toda fidelidad y lealtad. [...] Con esta confianza quedo rogando a la Divina Majestad, prospere y dilate la importante vida de Vuestra Excelencia por muchos años.

Popayán, 15 de febrero de 1822.

Merced María Collazos. (Fundación John Boulton, 1960, p. 267) 
Desde esa misma ciudad, María Cleofe Benito escribió una carta en la que relató cómo se había visto resignada a buscar con su propio trabajo la forma de proveer las atenciones básicas a sus tiernos vástagos debido a la prolongada ausencia de su esposo y el abandono económico en que la tenía sumida. Pero ante una inesperada enfermedad no vio más opción que exigir como medida extraordinaria el embargo del sueldo de aquel militar:

\section{Excelentísimo señor:}

La ciudadana María Cleofe Benito, mujer y conjunta persona de Cornelio Rodríguez, ante Vuestra Excelencia con todo mi respeto, parezco y digo: que en el Ejército del Sur se halla en la actualidad en clase de teniente del citado mi marido Cornelio Rodríguez. Ningún auxilio ha proporcionado para la subsistencia mía y de nuestros tiernos hijos. Con mi trabajo personal nos hemos mantenido hasta ahora pero faltándome las fuerzas para continuarlo por haberme enfermado, me veo en estado de mendigar para proporcionar el alimento a esas inocentes criaturas que perecerán, porque ya no encuentro socorro alguno. En esta virtud, llena de confianza, en la piedad y justificación de Vuestra Excelencia me acojo a su tan benigno corazón, y le suplico que atendida mi situación que es notoria, se digne Vuestra Excelencia acordar y mandar que del prest que se le debe contribuir al nominado mi marido, se le embargue la mitad, y se me de aquí, a mí, para los precisos objetos de alimentar nuestros hijos. Esta mi solicitud es de justicia y por ella a Vuestra Excelencia reverentemente suplico provea en su conformidad de que también recibiré merced que imploro en lo necesario. (Benito, 1821)

El 19 de septiembre de 1821 se envió el caso a Bogotá para que se dictara la respectiva resolución.

En otras circunstancias, la impetración de las mujeres era que se les dispensara alguna ayuda o medio de subsistencia económica para mitigar los efectos de la guerra. Como una forma de ver compensado el sacrificio heroico de su esposo, en el mes de octubre de 1819 una viuda tendera de la ciudad de Girón consiguió que el Libertador Simón Bolívar la eximiera de las contribuciones tributarias:

Excelentísimo señor:

La ciudadana Dolores Salgar, viuda del difunto José María Ordóñez, fusilado en Santafé por el gobierno español, hace presente a Vuestra Excelencia que rodeada de siete hijos todos menores, no logra que se tenga una consideración piadosa acerca de su situación. ¿Quién se persuadirá que se me tenga presente para pensionarme en las pensiones públicas tan solo porque me ven sujetas a una tienda en negociaciones de poca consideración? Así lo experimento; y cuando toco con la contemplación el poco fruto de mis agencias con que sostengo una familia crecida, no puedo menos que contristarme, llegando a un extremo casi de desesperación. En Vuestra Excelencia residen altas facultades para ocurrir los necesitados en solicitud de socorro. Yo lo hago suplicando a Vuestra Excelencia para que se sirva recomendarme a las Justicias a fin de que no me graven en las contribuciones públicas, compadeciéndose de mi situación y de la orfandad de mis hijos. 
Dios guarde a Vuestra Excelencia muchos años.

Ciudad de Girón, octubre 13 de 1819.

Dolores Salgar. (Fundación John Boulton, 1960, p. 59)

Un par de hermanas desamparadas aprovecharon la llegada del presidente Simón Bolívar a principios de 1820 a la ciudad de Bogotá para pedirle un pequeño auxilio:

Excelentísimo Señor:

Señor: la mísera situación en que me hallo, en unión de otra hermana, que ambas nos acogemos a la conocida piedad de Vuestra Excelencia suplicando se digne darnos una limosna para en algún modo remediar con ella nuestra necesidad. Cuya súplica hacemos de lo íntimo de nuestros corazones, no patentizando por menor lo que padecemos con la escasez y enfermedades; por no molestar a Vuestra Excelencia y porque estamos persuadidas de su inextinguible caridad.

Dios guarde a Vuestra Excelencia los muchos años que este pueblo necesite para su felicidad.

Bonifacia Sarmiento (Fundación John Boulton, 1960, p. 63).

Ascensión Cuevas, una dama oriunda de la villa ribereña de Mompox, dirigió una carta en agosto de 1820 al presidente Simón Bolívar suplicándole se le devolviera unas mercancías que le habían sido arrebatadas injustamente por un oficial republicano, las cuales eran importantes para aliviar sus necesidades. Para ello, puso de presente su malograda fortuna y el sacrificio de sus tres hijos a las banderas independentistas ${ }^{10}$ :

el estado de indigencia a que he quedado reducida con la opresión del Gobierno español en que no solo he aventurado mi fortuna sino sacrificado tres hijos que servían a la patria; uno el subteniente José María Sosa fusilado por [el general español Pablo] Morillo en Torrecilla; Marcos aprehendido en San Benito Abad por Sabanas y el otro Francisco Silvestre recientemente asesinado en Chiriguaná por una partida de descarriados que lo sorprendió, únicos objetos en que podía ayudar mi subsistencia en mi avanzada edad. He resuelto confiada en la notoria como sublime generosidad de Vuestra Excelencia dirigirle mis clamores [...] y así solo me contraigo a reclamar varios efectos de mercería que de mi pertenencia extrajeron en Simaña de orden del comandante Hermógenes Maza, como lo acredita la adjunta carta original que me pasó mi deudora, y puedo probar con los ciudadanos sargento de marina Anacleto Echávez y Diego Berrío. (Cuevas, 1820)

Fausta García, vecina de la Villa del Socorro, había entregado sus cuatro hijos a la causa republicana y por mandato expreso del gobierno de Reconquista todos fueron llevados al patíbulo entre septiembre y octubre de 1816. Al cabo

10 Sobre esta temática, véase el reciente trabajo de Ramírez (2019, pp. 45-57). 
de cinco años, ella elevó un memorial ante el gobernador militar de la provincia en el cual pone de presente los sacrificios de su familia:

Bien informado el excelentísimo señor Libertador de esta verdad y de que mis enunciados hijos eran los que me sostenían, me dio el estanquillo de Barichara. Pero como este beneficio va a cesar, según la ley, voy a volver a la miseria en que me dejó el enemigo [...] Le suplico mandar que el señor secretario de Gobierno certifique cuanto le conste de lo que dejo expresado sirviéndose igualmente vuestra señoría por un efecto de bondad, elevarlo todo con un apoyo al Supremo Poder Ejecutivo, a fin de que me proporcionen alguna pensión o destino con qué poder ocurrir a la subsistencia de mi familia (pues tenía tres hijas pequeñas).

El Socorro, mayo 8 de 1822.

Fausta García. (Forero, 1972, p. 17)

No existen rastros de haberse cumplido esta concesión, pero en la Gaceta de la Nueva Granada sí aparece una condonación del Gobierno a una deuda que había dejado su difunto marido.

\section{Las mujeres como intercesoras y la fuerza de los sentimientos}

Ante la gran cantidad de dificultades que entrañaba la guerra, bien supieron las mujeres aprovechar los escasos canales disponibles para interceder ante las autoridades en busca de mejor atención a sus esposos e hijos combatientes.

Sumamente complicada y caótica resultó la atención sanitaria de los combatientes en tiempos de guerra por la conjugación de una serie de factores: los tibios avances de la medicina, el abrumador número de heridos y enfermos en campaña, los precarios recursos disponibles para las medicinas y las falencias en el improvisado montaje de los hospitales militares (Quevedo, 2010, p. 212).

El siguiente fue el clamor de una dama residente en la Villa del Socorro que, ante la incertidumbre de las atenciones brindadas al interior del ejército patriota, pidió a las máximas autoridades le permitiesen llevar a su esposo herido a su casa para brindarle adecuadamente las curaciones necesarias:

Excelentísimo señor.

Joaquina Corujo, mujer legítima de Ignacio Otero, subteniente del batallón Bravo de Apure, vecino de la villa del Socorro, ante Vuestra Excelencia con la mayor moderación digo: que hace el espacio de siete años que el insinuado mi marido sirve en las tropas de la República con la más firme adhesión y constancia, sufriendo cuanto V.E. sabe que ha sufrido el Ejército Libertador de cuya resultas se halla en el día postrado en San Juan de Payare e imposibilitado de continuar en la carrera. Vuestra Excelencia en el Llano le dio su licencia pero verbal por cuyo motivo no ha podido hacer uso de ella hasta que se digne dársela por escrito. Permítale pues 
Vuestra Excelencia retirarse a su casa a ponerse en cura y tratar de recuperar su salud para que pueda desempeñar las obligaciones de padre de familia, ya que no puede continuar el servicio de las armas. Este beneficio concedido a una pobre mujer atraerá sobre V.E. las bendiciones del cielo y yo viviré eternamente reconocida.

Dios guarde a V.E. muchos años.

Socorro, junio 8 de 1820. (Corujo, 1820)

La decisión final se dejó a consideración del general Simón Bolívar, de quien dependía este militar.

La suerte estuvo del lado de María Josefa Moya a quien el alto mando militar de la ciudad de Bogotá accedió, a mediados de 1820, a dejar a su hijo en esta capital por cuestiones de salud. De este modo, él podía estar muy cerca de su madre y a la vez podía recuperarse de una enfermedad, con lo cual quedó postergada una orden de traslado:

habiendo Vuestra Excelencia tenido a bien reponer al empleo de subteniente a un hijo mío llamado Lucas Camacho con destino al batallón del Socorro; este oficial tuvo la desgracia de caer enfermo al tiempo mismo en que fue destinado y pensaba marchar, teniendo que reducirse a mi casa para recibir de mí el auxilio que en esta situación le podía suministrar a pesar de hallarme en mi viudedad sin ningún haber y rodeada de siete hijos a quienes tengo que alimentar trabajando de día y de noche. Así es que dicho oficial al cabo de cinco meses de enfermedad, aunque no está enteramente repuesto, quisiera por cumplir marchar a su destino; pero a más de que los médicos le dicen que entrando al temperamento del Socorro vuelve a caer enfermo por ir a un temperamento que en la actualidad no le adapta, aún no tiene los aperos que necesita y ni un par de mudas que llevar sin poderle ya aliviar en nada, pues Vuestra Excelencia puede informarse de la triste actuación de mi casa. Por tanto, mi súplica se dirige que siendo mi hijo más útil estando enteramente bueno y pudiendo marchar con alguna comodidad, pido a Vuestra Excelencia encarecidamente se sirva mandar se le incorpore en alguno de los cuerpos de línea de esta capital, que el día en que Vuestra Excelencia estime por conveniente, está pronto a seguir a cualquier destino. (Moya, 1820)

Del reducido acervo de cartas escritas por mujeres, son en realidad muy contadas aquellas de carácter privado y con mensajes de amor ${ }^{11}$. La comunicación postal en tiempos de guerra era bastante complicada debido a la interrupción de los canales oficiales de correo, las interceptaciones, además de las largas distancias, la agreste geografía e incluso la falta de papel. En medio de tantas vicisitudes, un mensaje para la mujer amada podía ser un incentivo en medio de los fragores de la lucha militar. Este es un conmovedor mensaje interceptado en enero de 1816 a un militar patriota que escribía desde Bucaramanga a su

Sobre esta temática vale traer a colación la selección de cartas privadas de algunas mujeres en 1811 publicadas por el historiador Hermes Tovar (1984). 
hija Manuela Navarro Negrón, residente en la ciudad de Ocaña, en medio de la zozobra tras la ocupación del Ejército de Reconquista española:

Hijita Manuela: ayer que llegué aquí te escribí por el camino de tierra, comunicándote que no hubo novedad en el tránsito, pues solo he padecido la incomodidad de una escocedura que me sobrevino desde las Lajas pero ya estoy mejor, y hoy sigo a Pie de Cuesta con el fin de ver si me regreso por el río como lo haré si [José Fernández de] Madrid vuelve con la fuerza que trajimos pues yo no deseo más que el reposo de casa, donde solo hallo tranquilidad. Vos no tengáis cuidado por mí pues nuestra Señora de Torcoroma ${ }^{12}$ me ha de llevar felizmente a esa. Espero no dejes de escribirme pues esto a más de que me consolaría mucho, me gobernará para todo cuanto convenga a mis movimientos. Saludos a todos y vos quédate y que Dios te guarde muchos años, que te desea tu querido Pepito. (Pepito, 1816)

Habría que mencionar, además, las solicitudes en busca de autorización para contraer matrimonio con algún militar. Según el Congreso de Angostura, los oficiales que quisieran casarse solo debían presentar permiso de sus superiores. (Congreso de Angostura, 1819)

Sobre esta temática, vale destacar esta comunicación escrita el 2 de agosto de 1820 por el militar Vicente Almeida, oriundo de la villa de Barichara:

Señor ministro de guerra Pedro Briceño Méndez:

Juzgando con bastante fundamente que el estado de aptitud en que se halla nuestra República ofrece en breve su absoluta Independencia, he creído poder solicitar permiso del Excelentísimo Señor Presidente para contraer esponsales con la señora Petronila Peñuela, vecina de esta villa, por tanto suplico a V. S. lo ponga en conocimiento para que determine lo que sea de su agrado.

Dios guarde a V. S. muchos años. Varaflorida ${ }^{13}$. (Almeida, 1820)

\section{Conclusiones y reflexiones}

Las veintiséis cartas recopiladas y las temáticas planteadas en este artículo solo pretenden ser una amable invitación a investigadores sociales e historiadores para que se animen a realizar exploraciones más exhaustivas en los archivos y en fuentes primarias impresas con miras a profundizar sobre la situación social, económica, política y sentimental de las mujeres en las guerras de la Independencia de Colombia. Nuevos sondeos a los procesos judiciales, archivos eclesiásticos, periódicos y fondos parroquiales y notariales aportarán reveladoras pistas que seguramente ayudarán a construir una visión más realista y equilibrada sobre la mujer, más allá de los estereotipos que aún siguen difundiéndose en algunos trabajos académicos.

\footnotetext{
12 Patrona de la ciudad de Ocaña.

13 Hoy municipio de Barichara, departamento de Santander.
} 
Las cartas aquí transcritas son interesantes testimonios documentales, antes desechados por los historiadores aficionados de primera generación, pero ahora sacadas a la luz por cuanto entrañan una mirada particular de la época, en la cual pueden observarse varios detalles del desarrollo mismo de la sociedad en aquellos tiempos de guerra.

Aún con todas las dificultades, no hay duda de que estas integrantes del género femenino buscaron la forma de acudir ante las instituciones legalmente establecidas y ante los órganos de justicia para elevar sus solicitudes y reclamaciones que redundaran en alivios y soluciones a sus complicaciones sociales, familiares y económicas. Este hecho refleja una mayor irrupción de las mujeres en el escenario de lo público (Martínez, 2012, p. 7). A través de las líneas de aquel acervo epistolar puede corroborarse cómo ellas se constituyeron en el eje nodal de sus grupos familiares en momentos en que, por efectos de las bajas de hombres combatientes ocasionadas por la incesante lucha militar, paralelamente aumentaba de manera considerable el número de viudas y madres solteras (Rodríguez, 1996, pp. 228-229).

Con sus escasos recursos materiales y jurídicos, ellas supieron canalizar esas expectativas y demandas, para lo cual pusieron de presente su solidaridad y compromiso con la causa política. Todo esto apunta a pensar que supieron comprender cada una de las coyunturas y desarrollaron una conciencia política manifestada a través de la interacción que sostuvieron con las autoridades republicanas y monárquicas por medio de peticiones y reclamaciones (Serrano, 2017, p. 97). Vale destacar, además, su persistencia en buscar atención en distintas instancias de poder hasta el punto de convertirse en actores activos durante este proceso de emancipación. Todo esto no hace más que remarcar la revalorización del rol de ellas en esa etapa de transición hacia la República, con lo cual empezaron a recorrer el camino que les permitiría superar las restricciones que la sociedad colonial les había impuesto como esposas, madres y religiosas (Blanco y Cárdenas, 2009, pp. 155-156) dentro de una estructura social altamente jerarquizada, patriarcal y excluyente.

Tras un tardío reconocimiento de sus derechos civiles y ciudadanos (Lux, 2019, pp. 76-91), nuevos retos y vicisitudes afrontarían las mujeres en las décadas venideras tras el impacto de las guerras civiles (Jaramillo, 1995) que asolaron gran parte del territorio de Colombia y las guerras posteriores del siglo XX. 


\section{Referencias}

Gazeta Ministerial de Cundinamarca (1814, 27 de enero). Noticias. (No. 123), 691

Rodríguez, N. (1820). [Carta de solicitud presentada a las autoridades republicanas]. Archivo General de la Nación, Fondo Secretaría de Guerra y Marina, tomo 3, f. 856r-v.

Academia Colombiana de Historia (1916). Archivo Santander. Águila Negra Editorial.

Alfonsa, I. (28 de junio de 1820). [Carta a las autoridades republicanas en solicitud de licencia absoluta]. Archivo General de la Nación, Fondo Secretaría de Guerra y Marina, tomo 2, f. 584r.

Algarra, J. (22 de enero de 1813). [Carta dirigida a las autoridades de Bogotá]. Archivo General de la Nación, Fondo Historia, tomo 7, ff. 181r-182r.

Almario, O. (2013). Castas y razas en la independencia neogranadina 1810-1830. Identidad y alteridad en los orígenes de la Nación Colombiana. Universidad Nacional de Colombia.

Almeida, V. (2 de agosto de 1820). [Carta dirigida al secretario de Guerra Pedro Briceño Méndez]. Archivo General de la Nación, Fondo Secretaría de Guerra y Marina, tomo 2, f. 522r.

Araos, J. (25 de febrero de 1820). [Solicitud para el retorno de sus hijos reclutados en el ejército]. Archivo General de la Nación, Fondo Secretaría de Guerra y Marina, tomo 2, f. 520r.

Arce, J. (septiembre de 1820). [Carta dirigida a las autoridades republicanas]. Archivo General de la Nación, Fondo Secretaría de Guerra y Marina, tomo 6, f. 953r.

Arias, Y. A. (2015). Una mirada historiográfica a las mujeres tunjanas en el período de la independencia, 1810-1819. Historia y Sociedad, 28, 143-165. http://dx.doi.org/10.15446/hys.n28.48015

Beltrán, M. (24 de junio de 1820). [Carta dirigida a las autoridades republicanas]. Archivo General de la Nación, Fondo Secretaría de Guerra y Marina, tomo 2, f. 645 r.

Benito, M. C. (18 de septiembre de 1821). [Solicitud de embargo del sueldo de su esposo]. Archivo General de la Nación, Fondo Secretaría de Guerra y Marina, tomo 6, f. 1.036r-v.

Blanco, J. y Cárdenas, M. (2009). Las mujeres en la historia de Colombia, sus derechos, sus deberes. Prolegómenos, 12(23), 143-158. https://doi.org/10.18359/prole.2501

Bonilla, H. (ed.) (2010). Indios, negros y mestizos en la Independencia. Planeta.

Borreguero, C. (2016). La historia militar en el contexto de las nuevas corrientes historiográficas. Una aproximación. Manuscrits. Revista d'història Moderna, 34, 145-176. https://doi.org/10.5565/rev/ manuscrits. 87

Calderón, G. (1 de noviembre de 1819). [Carta dirigida al presidente Simón Bolívar]. Archivo General de la Nación, Fondo Secretaría de Guerra y Marina, tomo 323, ff. 935r-936v.

Cherpak, E. (1995). Las mujeres en la Independencia. Sus acciones y sus contribuciones. En M. Velásquez (Comp.), Las mujeres en la historia de Colombia. Tomo I. (pp. 83-116). Editorial Norma.

Congreso de Angostura. (1819). [Ley sobre matrimonio de los militares patriotas]. Archivo General de la Nación, Fondo Secretaría de Guerra y Marina, tomo 333, f. 180r.

Corrales, M. E. (1883). Documentos para la historia de la provincia de Cartagena de Indias. Tomo II. Imprenta de Medardo Rivas. 
Cortázar, R. (comp.) (1969). Correspondencia dirigida General Francisco de Paula Santander. Tomos IV, VIII y IX. Academia Colombiana de Historia.

Corujo, J. (8 de junio de 1820). [Solicitud a las autoridades republicanas para atender a su esposo herido]. Archivo General de la Nación, Fondo Secretaría de Guerra y Marina, tomo 2, f. 817r-v.

Cuevas, A. (5 de agosto de 1820). [Carta dirigida al presidente Simón Bolívar]. Archivo General de la Nación, Fondo Secretaría de Guerra y Marina, tomo 2, f. 832r-v.

De la Pedraja, R. (1984). La mujer criolla y mestiza en la sociedad colonial, 1700-1830. Revista Desarrollo y Sociedad, 13, 199-229. https://doi.org/10.13043/dys.13.9

Delgadillo, R. (25 de febrero de 1820). [Carta dirigida al vicepresidente Francisco de Paula Santander]. Archivo General de la Nación, Fondo Secretaría de Guerra y Marina, tomo 331, f. 349r.

Díaz, P. (2015). Historia social e historia cultural de las mujeres. Apuntes para un debate. Revista de Historiografía, (22), 13-23. https://e-revistas.uc3m.es/index.php/REVHISTO/article/view/2644

Forero, P. (1972). Las heroínas olvidadas de la Independencia. Ministerio de Educación Nacional.

Fundación John Boulton (1960). Acotaciones Bolivarianas. Decretos marginales del Libertador (1813-1830).

García, A. B. (2013). Las heroínas silenciadas en la Independencia Hispanoamericana. Ediciones Complutenses.

Garrido, M. (1993). Reclamos y representaciones: variaciones sobre la política en el Nuevo Reino de Granada, 1770-1815. Banco de la República.

Garzona, G. (8 de octubre de 1821). [Carta dirigida a su esposo Salvador Bastidas]. Archivo General de la Nación, Fondo Secretaría de Guerra y Marina, tomo 6, f. 1.012r-v.

Gómez, A. (1978). Mujeres heroínas en Colombia y hechos guerreros. Talleres Gráficos de Interpres.

González, J. C. (2018). Representaciones sobre las mujeres en la Independencia: entre realidad y ficción, 1810-1830. Universidad del Valle.

González, N. (3 de mayo de 1820). [Carta dirigida al presidente Simón Bolívar en solicitud de licencia absoluta]. Archivo General de la Nación, Fondo Secretaría de Guerra y Marina, tomo 3, f. 124r-v.

Gutiérrez, D. (2016). La Restauración en la Nueva Granada (1815-1819). Universidad Externado de Colombia.

Herrera, M. J. (noviembre de 1820). [Carta de defensa ante los señalamientos por auxiliar a desertores]. Archivo General de la Nación, Fondo Secretaría de Guerra y Marina, tomo 329, ff. 87r-88v.

Jaramillo, C. E. (1995). Mujeres en guerra. Participación de las mujeres en los conflictos civiles. En M. Velásquez (dir.), Las Mujeres en la Historia de Colombia. Tomo II. Mujeres y sociedad (pp. 359-386). Grupo Editorial Norma.

Kalmanovitz, S. (2008). Consecuencias económicas del proceso de Independencia en Colombia. Fundación Universidad de Bogotá Jorge Tadeo Lozano. https://www.utadeo.edu.co/sites/tadeo/files/node/ publication/field_attached_file/pdf-_consecuencias-_pag-_web_16_0.pdf

Losada, F. (agosto de 1820). [Carta dirigida al presidente Simón Bolívar]. Archivo General de la Nación, Fondo Secretaría de Guerra y Marina, tomo 3, f. 346r.

Lux Martelo, M. E. (2014). Mujeres patriotas y realistas entre dos órdenes. Discursos, estrategias y tácticas en la guerra, la política y el comercio (Nueva Granada, 1790-1830. Universidad de Los Andes. 
Lux Martelo, M. E. (2019). Mujeres y ciudadanía en las primeras décadas del siglo XIX neogranadino. Boletín Cultural y Bibliográfico, 53(97), 76-91. https://publicaciones.banrepcultural.org/index. $\mathrm{php} /$ boletin_cultural/article/view/20883

Martínez, A. (1997). Presencia femenina en la historia de Colombia. Academia Colombiana de la Historia.

Martínez, F. (2012). Independencia en femenino. En F. Martínez (coord.), Heroínas incómodas. La mujer en la Independencia de Hispanoamérica (pp. 5-14). Ediciones Rubeo.

Monsalve, J. D. (2010). Las mujeres en la Independencia (2 ${ }^{a}$ edición). Academia Colombiana de Historia.

Montoya, E. (1972). La criolla Policarpa Salavarrieta. Colcultura.

Morales, A. (25 de febrero de 1820). [Carta del comandante general del Socorro, Antonio Morales a las mujeres de la villa del Socorro]. Archivo General de la Nación, Fondo Secretaría de Guerra y Marina, tomo 331, f. 350r.

Moya, M. J. (12 de junio de 1820). [Carta de solicitud de atención a su esposo enfermo]. Archivo General de la Nación, Fondo Secretaría de Guerra y Marina, tomo 3, f. 558r-v.

O'Leary, S. B. (1983). Memorias del General O'Leary. Imprenta de la Gaceta Oficial.

Pepito. (20 de enero de 1816). [Carta dirigida a su hija Manuela Navarro]. Academia Colombiana de Historia, Fondo Archivo del General Miguel de La Torre, tomo XX, p. 78.

Peralta, V. y Quintero, I. (2020). Vida Cotidiana, familiar y afectiva durante la Independencia a través de la correspondencia femenina. Nueva Granada y Venezuela, 1810-1830. Academia Colombiana de Historia.

Pino, J. M. (27 de abril de 1820). [Solicitud de traslado de su esposo, militar del ejército patriota]. Archivo General de la Nación, Fondo Secretaría de Guerra y Marina, tomo 3, f. 795r-v.

Quevedo, E. (2010). Independencia y medicina: una polémica bogotana entre médicos criollos y franceses. Credencial Historia, 250, 201-214. https://www.banrepcultural.org/biblioteca-virtual/ credencial-historia/numero-250/independencia-y-medicina-una-polemica-bogotana-entre-medicoscriollos-y-franceses

Ramírez, M. H. (2019). Las madres y viudas de la Independencia. Boletín Cultural y Bibliográfico, 53(97), 45-57. https://publicaciones.banrepcultural.org/index.php/boletin_cultural/article/view/20881

Riveros, M. (2 de agosto de 1816). [Denuncia ante las autoridades españolas]. Archivo General de la Nación, Fondo Purificaciones, tomo 2, f. 29r

Rodríguez, A. N. e Ibarra, M. E. (2013). Los estudios de género en Colombia. Una discusión preliminar. Sociedad y Economía, 24, 15-46. https://sociedadyeconomia.univalle.edu.co/index.php/sociedad_y_ economia/article/view/3977/6105

Rodríguez, P. (1996). Composición y estructura de las familias urbanas en el Nuevo Reino de Granada (siglo XVIII). En: J. H. Borja Gómez (ed.), Inquisición, muerte y sexualidad en la Nueva Granada (pp. 199-241). Editorial Ariel-CEJA.

Santander, F. P. (1819). Reglamento para la conservación de los Ejércitos de la República. (1819). [s. n.].

Serrano, A. (2017). Conciencia política de las mujeres durante la Independencia de la Nueva Granada. El caso de Santafé entre 1810 y 1820. Secuencia, 97, 61-103. http://secuencia.mora.edu.mx/index. $\mathrm{php} /$ Secuencia/article/view/1448 
Tovar, H. (1984). Cartas de amor y guerra. Anuario de Historia Social y de la Cultural, 12, 155-196. https:// revistas.unal.edu.co/index.php/achsc/article/view/36181/37644

Valencia, A. (2001). Mujeres Caucanas y sociedad Republicana. Anzuelo Ético Ediciones.

Villegas, C. (2006). Del hogar a los juzgados: reclamos familiares ante la Real Audiencia de Santafé a finales del período colonial, (1800-1809). Revista Historia Crítica, 31, 101-120. https://revistas. uniandes.edu.co/doi/abs/10.7440/histcrit31.2006.04 